\title{
NEW APPROACHES FOR
}

\section{TEACHING, LEARNING AND}

\section{USING INFORMATION AND}

\section{COMMUNICATION}

\section{TECHNOLOGIES IN EDUCATION'}

\section{Tjeerd Plomp, Alfons ten Brummelhuis and Willem J. Pelgrum}

\section{What is the direction for the future of learning?}

Computers, especially when they are linked in networks, have the potential to dramatically change everyday classroom practice. The impact of the use of information and communication technology (ICT) in education will not be limited to the actors involved in the learning process (teachers and students), but will also change the institutional infrastructure, relations and patterns of behaviour within the education system, and even the content of education. For a good understanding of these educational changes it is necessary to look at the transformation industrialized societies are undergoing.

Education is reacting to the emergence of the information society. Traditionally, schools provided the settings where individuals were prepared for the industrial society. In this society the focus was on 'making things', on industrial production. Today's edu-

\section{Original language: English}

\section{Tjeerd Plomp, Alfons ten Brummelbuis and Willem J. Pelgrum (Netherlands)}

The authors are working at the Faculty of Educational Science and Technology, University of Twente, Enschede. Tjeerd Plomp, Department of Curriculum, was chair of the international steering committee of the International Association for Educational Achievement (IEA) CompEd Study and is, since 1990, chair of IEA. He is also the chair of COMMITT, the Committee on Multimedia in Teacher Training, an advisory committee to the Dutch Minister of Education, Culture and Science. Alfons ten Brummelhuis is working at OCTO, the Center of Applied Research on Education of the Faculty of Educational Science and Technology. He is secretary of COMMITT. His Ph.D. research was based on CompEd data. Willem J. Pelgrum, also at OCTO, was the international co-ordinator of the IEA CompEd Study. Co-author of several published studies. 
cation system faces the challenge to prepare individuals for the information society in which one of the most important aims is to handle information. Such a shift in focus can be seen as a new stage of our society, characterized by a new predominant paradigm. A simple overview of the successive stages of development of our society is depicted in Figure 1.

FIGURE 1 . Successive stages in the development of society

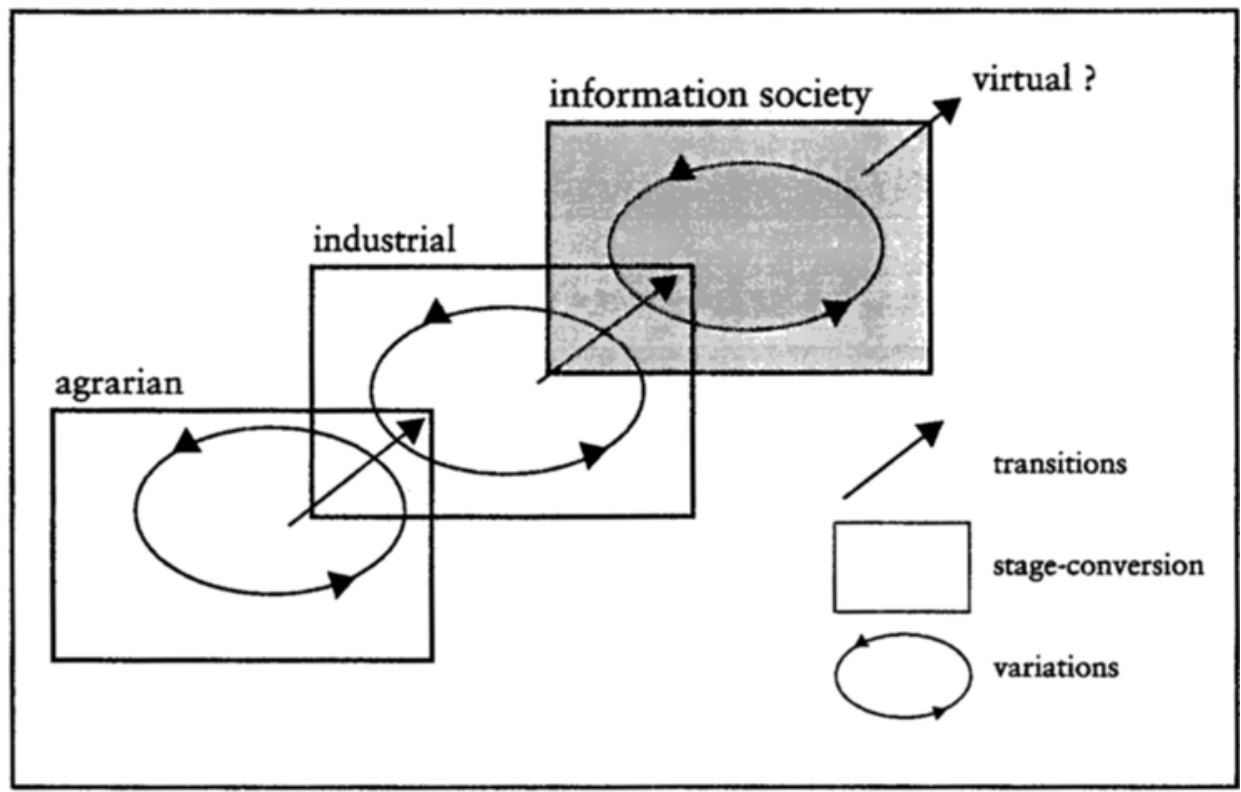

Source: COMMITT, 1996.

The stages in themselves are not stable: in each stage, changes and developments are taking place continuously, but these changes tend to stay within the boundaries of the dominant paradigm and the reigning technology. The problems faced are basically variations of common practice, while the order of things is kept in place. After a period of time, successive variations get less effect and tension grows until the next stage is apparent and a transition takes place. The conversion to a next stage is influenced by the availability of a catalyst of some kind (money, new energy sources or technological developments such as computers, networks, etc.).

In general terms, the mission of the education system is: to provide balanced, personal, social and vocational education; to facilitate personal growth, development and citizenship; and to prepare students for a profession. Quality of education can be defined as the degree to which education is capable of realizing these goals. In addition to the challenge of preparing individuals for the information era, the education system is facing other challenges:

- Education is expected to contribute towards the solution of social, cultural and economic problems of society. Education can no longer remain uninvolved in all of the problems of society: isolation, ethnic integration, juvenile delinquency, unemploy- 
ment, etc. There is massive evidence that one's level of education correlates directly to the opportunities one has in society (see various OECD reports published between 1988 and 1994).

- People want education to be individualized and flexible, suited to their specific needs. Growing individualization in and diversification of society calls for specific approaches in education. Standardized methods and classroom approaches will no longer be sufficient for individual needs.

- Life-long learning and new demands for learning are rising. The 1994 report of the SCP (the Dutch national office of social and cultural studies) states that the main issue to be addressed by the educational community is the growing number of people participating in education. Under the current circumstances, the guarantee for open and equal access to education for everybody is becoming almost unaffordable. It can be concluded that the near future provides all kinds of challenges and opportunities for the education system in our society. Managing large amounts of information, developing learning strategies to facilitate effective learning, and assuring that all citizens are skilful in assessing, selecting and dealing with information are of critical importance. It is assumed that a new balance is needed between teacher-oriented arrangements of the learning process and student-oriented arrangements, with much more emphasis given to the latter. ICT provides a means to bring about the revolutionary changes called for by the evolutionary transitions in society. As a tool to support the learning process, ICT holds a promise of new solutions for the challenges facing education.

\section{DIFFERENT SCOPES FOR THE USE OF ICT IN EDUCATION}

The use of ICT as part of the learning process can be subdivided in three different forms: as an object, aspect or medium (Netherlands, 1992). In addition, ICT is often used as a tool for organization and management in schools. In the latter case ICT is not integrated in the actual learning process but provides support to it at the classroom or school level (an example of an ICT application for organization and management purposes is a student-monitoring system).

The use of ICT in education as an object refers to learning about information technology and is mostly organized in a specific course such as 'computer education' or 'informatics'. As an object, ICT has been broadly implemented in the curricula of schools, especially in secondary education. Following the 'ICT-as-object-courses', students familiarize themselves with the most important 'ins and outs' of information technology as a dominant phenomenon in society. Its educational aim is the prevention of computer illiteracy. At present, education is quite good at this. But we have to take Walker's (1986) warning seriously, namely that the easiest way to meet the challenge of technological revolution is to create and implement a new subject so that the existing subjects do not have to change.

ICT as an aspect refers to specific applications of ICT in education as used in industry and professional practice. For the most part, such use in education is found in vocational education, for example in the training for computer-aided design (CAD), computer- 
aided manufacturing (CAM) and computer-mediated accounting. Vocational training in these areas is unthinkable without ICT integrated into it. ICT as an aspect also appears outside the vocational territory in subjects that are no longer teachable without the technology-for example, in general education experiments in science education, or accounting as a part of economics. For that reason ICT has become an obligatory part of the general exams in science and economics in general secondary education in the Netherlands. The educational aim of ICT as an aspect in education is job preparation.

Today, ICT as an object and as an aspect are firmly embedded in our educational practice.

A third form of use is ICT as a medium for teaching and learning. This refers to ICT as a tool for teaching and learning itself, the medium through which teachers can teach and learners can learn. ICT as a medium appears in many different forms, such as drilland-practice exercises, simulations, tutorials, individual learning systems (ILS), educational networks, hypermedia programmes, test-generating systems, etc. We speak of ICT as a medium whenever ICT is used to support the teaching and learning process and not specifically its content (which is the case when ICT is used as an object of learning). Current actual use of ICT as a medium is rare, though there is a growing interest in this application.

In this paper we will focus on the use of ICT as a medium in learning and teaching.

\section{ICT AS A MEDIUM TO ENHANCE THE LEARNING PROCESS}

For a good understanding of the potential of ICT for teaching and learning, it is important to have a closer look at the learning process. Figure 2 provides a general overview of aspects influencing the learning process. The learning process is represented as a field in which four forces operate. The horizontal dimension represents the relation between the actors in the learning process: the teacher and the learner. The vertical dimension represents the learning infrastructure, consisting of content, and teaching and learning materials. The learning process takes place at the cross-section of these four forces. The contribution at the level of school organization and management to the arrangement of the learning process (e.g. by provision of a student-monitoring system) is represented by the outer circle.

The figure illustrates the view that a learning process is the result of both structural conditions derived from the learning infrastructure and personal characteristics of the actors involved, and their interaction. Changing just one of the driving forces may lead to tensions, but not necessarily to substantial changes and improvement of the learning process. The introduction of ICT in the learning process, as a medium for learning, obviously changes the learning infrastructure in terms of materials and technical infrastructure. But only in conjunction with changes in the roles of the teacher and the student, and with changes in the organization of the content, is it possible to make use of the potential that ICT holds for enhancing the learning process. 
FIGURE 2.The infrastructure and actors of the learning process

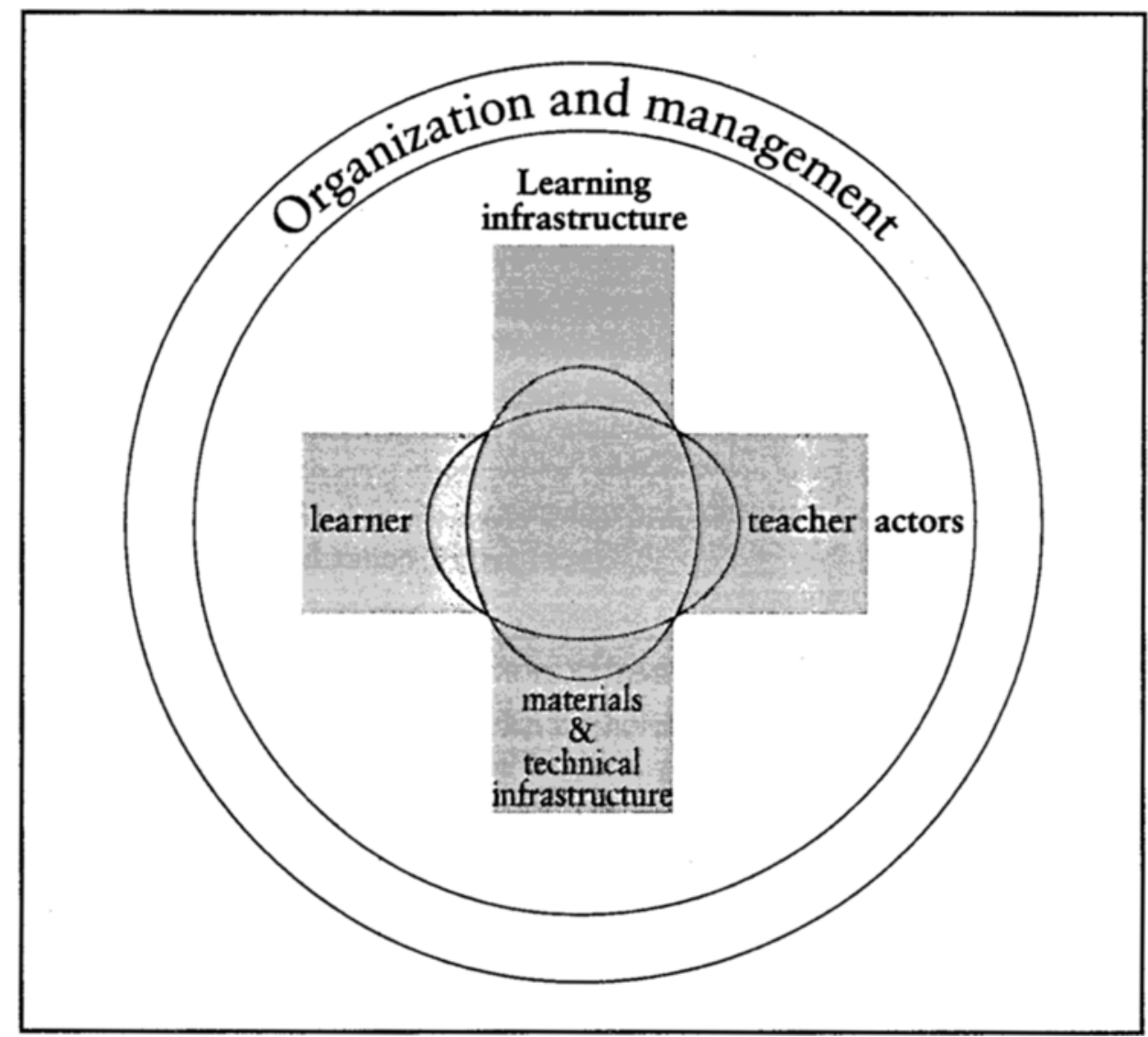

In addition to the above-mentioned dimensions of the learning process at the school level, changes in the learning process have to be supported by the public administration as well. It is hard to imagine how ICT as a medium can be implemented in a way that it has an impact on the role of the teacher without proper policy measures at the level of the national government. For instance, installing computers and software for an integrated learning system is one step and a relatively simple one compared to what has to be done for a structural change in the role of the teacher (needs consent by teachers, teachers unions, management, government), a commitment to more student-oriented learning (needs organizational measurements to regulate the use of school resources), and a focus on learning which is often labelled as 'constructive learning'. Learning is, in this view, perceived as an active, constructive, goal-oriented and situated process.

THE LEARNING PROCESS IN MORE DETAIL

Adjusting education to the societal needs of the future (the information society) means that schools have to enable learners to be continuously active in the sense of lifelong learn- 
ing. Stimulating and supporting this process of continuous learning implies the elaboration of suitable learning processes in which the learner learns how to become more or less an architect of his/her own learning processes. This means that learners have to be more involved in the arrangement of their own learning process. However, learning always refers to a process in which the learner needs support in terms of well-adapted subject matter content, organization of learning activities by a teacher, adequate materials and technical infrastructure. It is assumed that ICT has the potential to enhance such a learning approach that prepares students for the information society.

The use of ICT as part of the learning infrastructure and its relation to the role of the actors in the learning process (learner and teacher) can be clarified by looking in more detail at the characteristics of the teaching and learning process. Table 1 provides an overview of the activities that can be distinguished in relation to the leaming process (Simons and Zuylen, 1995). The set of activities refers to three main types of activities in the learning process: preparation, instruction and evaluation.

TABLE 1. Activities in the learning process

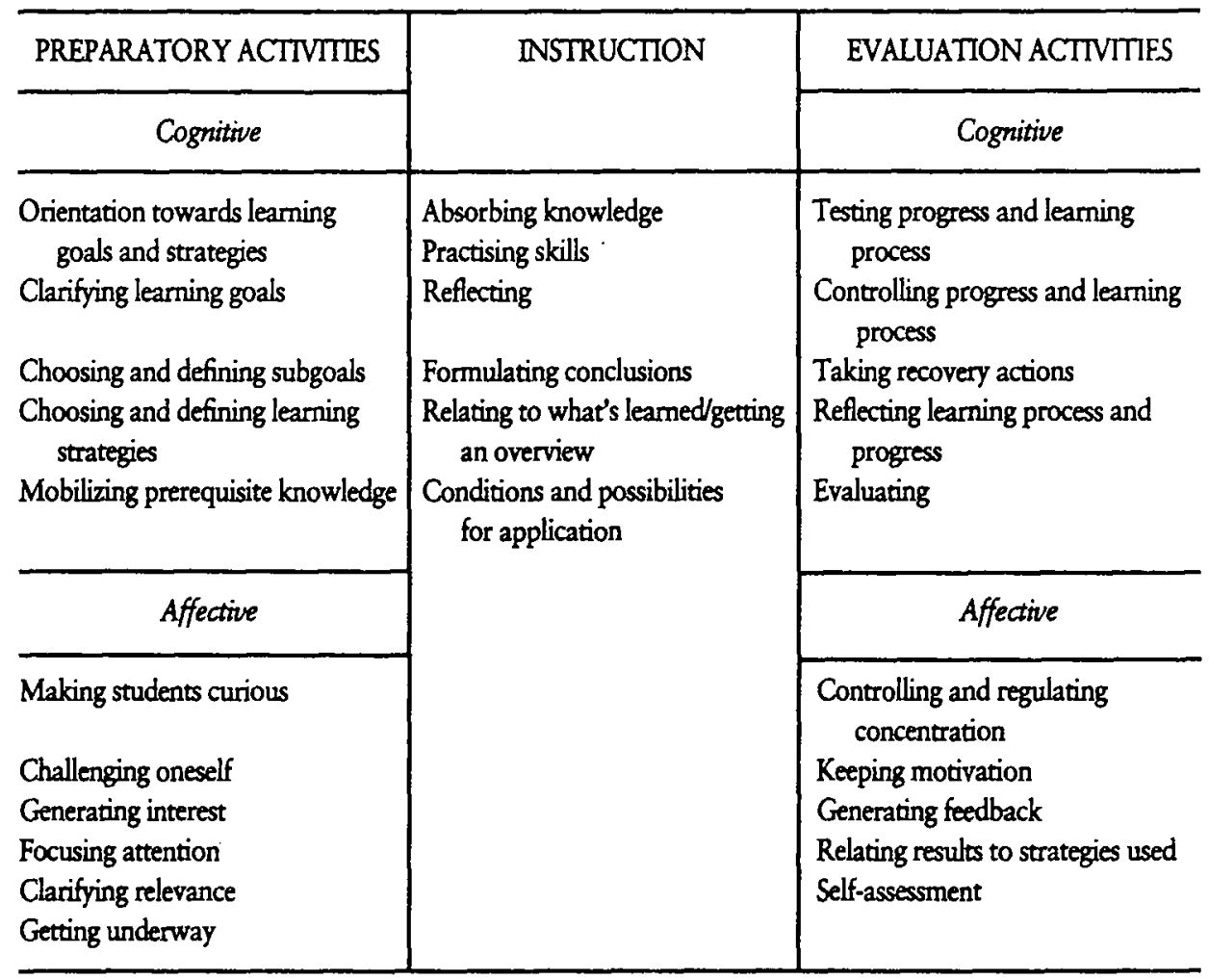

Source: Simons \& Zuylen, 1995.

In a traditional arrangement of the learning process, most of the activities listed in Table 1 are under the teacher's control. If a learning process is more student-oriented, it 
means in operational terms of the activities listed in Table 1 that the student becomes more responsible for some of the activities which are completely under control of the teacher in the teacher-oriented learning process. It is assumed that a shift from teacher-oriented arrangements of the learning process towards more student-oriented arrangements can be facilitated by ICT. However, until now this potential of ICT has hardly been implemented. Student-oriented learning processes are still rare, and most of the current ICT applications are used as far as they facilitate the teacher-oriented arrangements of the learning process. Applications of ICT are adapted to the existing teaching routines: the beliefs and attitudes of teachers towards their teaching practices do not change, and basically the teaching and learning process itself does not change.

For the development of effective strategies to use ICT to enhance learning and teaching it is important that we realize that the present use of ICT is just a substitution of the current teaching and learning activities. This substitution use can be seen as the first out of three phases through which the implementation of new technologies diffuses in general and therefore also in education (Itzkan, 1994).

\section{PHASES OF TECHNOLOGICAL DIFFUSION}

The three phases of technological diffusion are shown in Figure 3. In the substitution phase, the technology replicates or automates the existing instructional practices. The technology is used for activities which people already do in education, e.g. drill-and-practice exercises on the computer refer to the use of computers as 'electronic paper'. This kind of use is not bringing about real change in education, and therefore by its character will not meet the real needs of education in an information society as discussed above.

New instructional methods begin to evolve in the transition phase, for example the use of e-mail in foreign language classes to communicate with peers who are native speakers. In this phase the technology is used for activities for which it was not necessarily brought in, and it challenges old instructional practices.

In the transformation phase, the final phase of technology diffusion, the technology provides completely new instructional situations and the old customs may become obsolete. The instructional tasks for which the technology was originally acquired may no longer be desired.

The underlying rationale of the phases of technological diffusion is that it is a mistake to suppose that new technologies will continue to fit existing or old practices. If we continue to use ICT only as a substitution for existing practices, ICT will not contribute to solutions for today's problems in education. We might be left with only artificial interventions that by their nature provide no way out for the problems of continuous harsh budget cuts (solution: more money), multi-cultural students (solution: more teachers), a constantly changing economy (solution: more specialized subjects) and high unemployment (solution: more study).

It is important to note that in a traditional, mostly teacher-oriented educational setting the teacher is completely responsible for the arrangement of most of the learning activities. It is inevitable that the role of the teacher will increasingly change if the student is more actively involved in his or her own learning process and ICT is adopted to support an increasing number of learning activities. 
FIGURE 3. Phases of technological diffusion

\section{Substitution}

Automates existing instructional methods

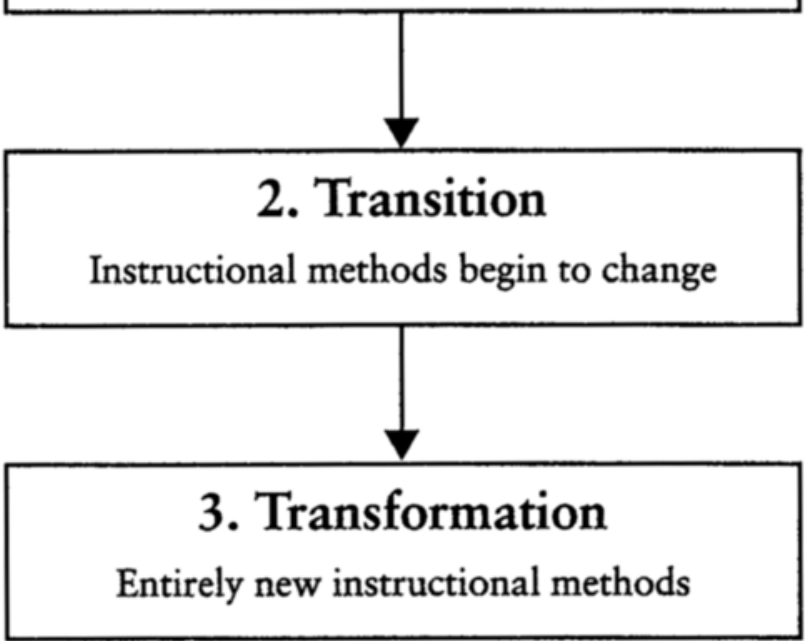

Source: Itzkan, 1994.

Although it is uncertain to what amount this shift will take place and how much time this will require, the direction of future change is clear: the learner will become more responsible for the arrangement of his/her own learning process. Or in other words, a new balance between student-oriented and teacher-oriented arrangements is needed to have education meet the challenges of the information society.

An important question in this context is to what extent our present education systems are already changing in this direction and whether the use of ICT is reflecting the transition phase.

\section{Where are we in the early 1990 s?}

Where the first section of this paper addressed the question of the future direction of education and the potential of ICT to help reach this future, this part discusses where we are in the early 1990s. Knowing where we are is important baseline information for policy makers and those in charge of shaping the future of our education, as it provides the starting point for determining the route to the future.

\section{THE IEA COMPUTERS IN EDUCATION STUDY}

The Computers in Education Study of IEA (International Association for the Evaluation of Educational Achievement) provides information about the status of information technology in education in a number of countries in 1989 and 1992. The major aim of the 
study was to build a knowledge base from which answers about the what and the bow of the use of computers in education could be obtained.

It is important to realize that the Computers in Education (CompEd) study took place in a period during which personal computers were the dominant form of information and communication technology used in schools. When the preparation for the CompEd study started in 1986, personal computers could almost not be handled without a basic knowledge of programming, while by the early 1990 s computer users had access to many easy-to-use tools. During the 1980s, due to many initiatives of schools and teachers and stimulation policies of governments, computers also became available to schools. They were mainly used for computer literacy type of courses (in secondary education) and electronic drill-and-practice exercises (in primary education).

The CompEd study focused on primary and secondary education. Data were collected in 1989 and 1992. In 1989 twenty countries participated in the study with national samples of both computer using and non-using schools, and using as well as non-using teachers of computer education, mathematics, mother tongue and science. In 1992 data were collected at the school, teacher and student levels in twelve countries.

The general broad indicators for which quantitative data were collected in each stage are listed in Table 2 . The rationale for selecting these indicators has been extensively described in CompEd publications, for example Pelgnum and Plomp (1993).

TABLE 2. Overview of main indicators collected in 1989 and 1992 in the CompEd study

\begin{tabular}{ll}
\hline Educational level & Indicators \\
\hline Country & National policies \\
& School system characteristics \\
\hline School & School policies \\
& Experience with computers \\
& Hardware availability \\
& Software availability \\
& Attitudes of the school principal \\
& Organization of computer use \\
& Type of use \\
& Staff development \\
& Number of using teachers \\
\hline Class/teacher & Teacher use \\
& Teacher knowledge \\
& Teacher training \\
\hline Class/student & Student knowledge \\
& Student attitudes \\
& Student school use \\
& Student home use
\end{tabular}

Source: CompEd study. 
Data about the use of computers in education have been collected from over 20,000 teachers, 10,000 schools and 150,000 students.

\section{SOME EXEMPLARY RESULTS}

The results of the CompEd study have been described in numerous publications (for example, Pelgrum and Plomp, 1991, 1993; Pelgrum, Janssen Reinen and Plomp, 1993). Here we present only a few results based on the data of four industrial countries (Austria, Japan, the Netherlands and the United States) to illustrate that the use of ICT in education was still in its infancy in the early 1990s, even in industrial countries.

From the results the picture emerges that during the 1980s and the beginning of the 1990 s the number of computers available in schools had rapidly increased (see Figure 4). A further growth can be expected. Noteworthy is the 'late start' of Japan.

FIGURE 4. Percentage of lower secondary schools with computers

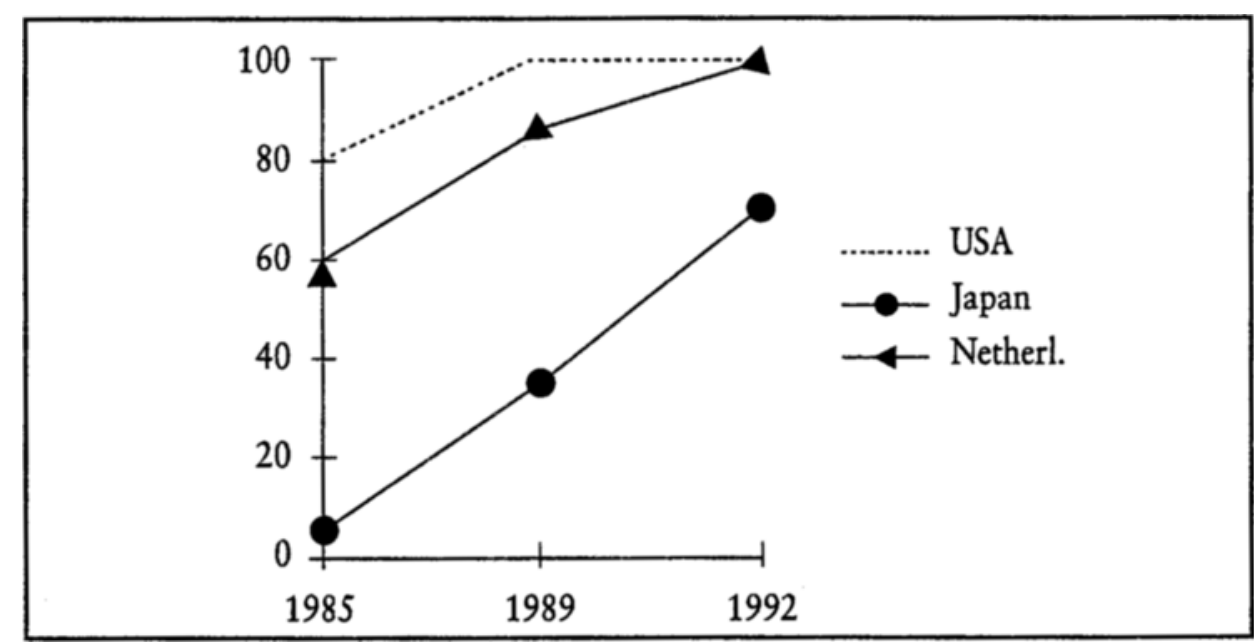

FIGURE 5. Average number of computers in lower secondary schools

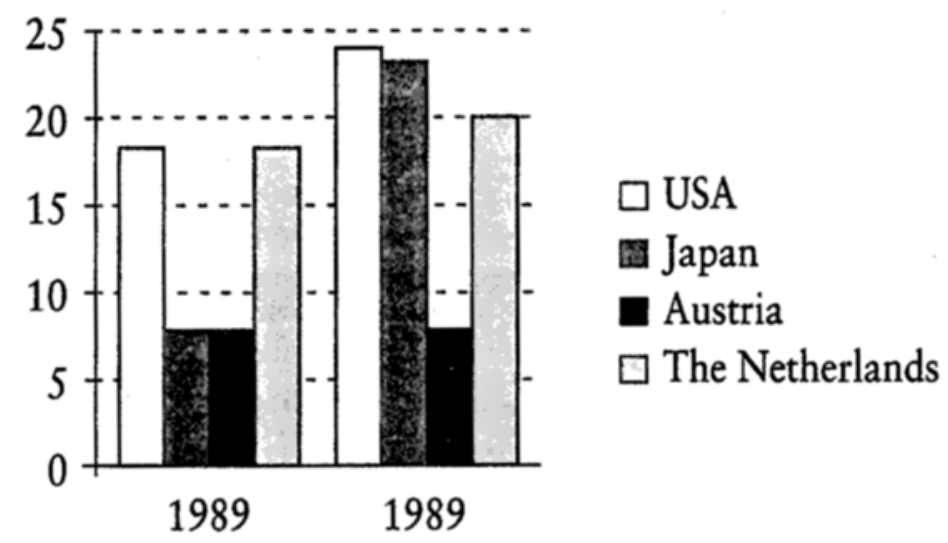


In 1992, however, the number of computers in typical schools was just enough to allow one class at a time to use them (Figure 5). Thus, in 1992 the hardware infrastructure in general (even in industrialized countries) was not sufficient to allow a broad and intensive use of information technology within the schools.

Particularly important in the recent past has been the development of electronic networks. The CompEd data show that in 1992 there were hardly any schools which had regular access to external networks, except for in the United States where $17 \%$ of lower secondary schools and $12 \%$ of elementary schools were using computers almost weekly for access to external networks (Pelgrum, Janssen Reinen \& Plomp, 1993, p. 17).

The lack of sufficient software was a major problem in 1989 (Figure 6). This substantially decreased between 1989 and 1992 . The most common didactical approach was drill-and-practice and tutorial programmes, which means automating already existing methods (i.e. substitution use of technology).

FIGURE 6. Percentage of lower secondary schools lacking software

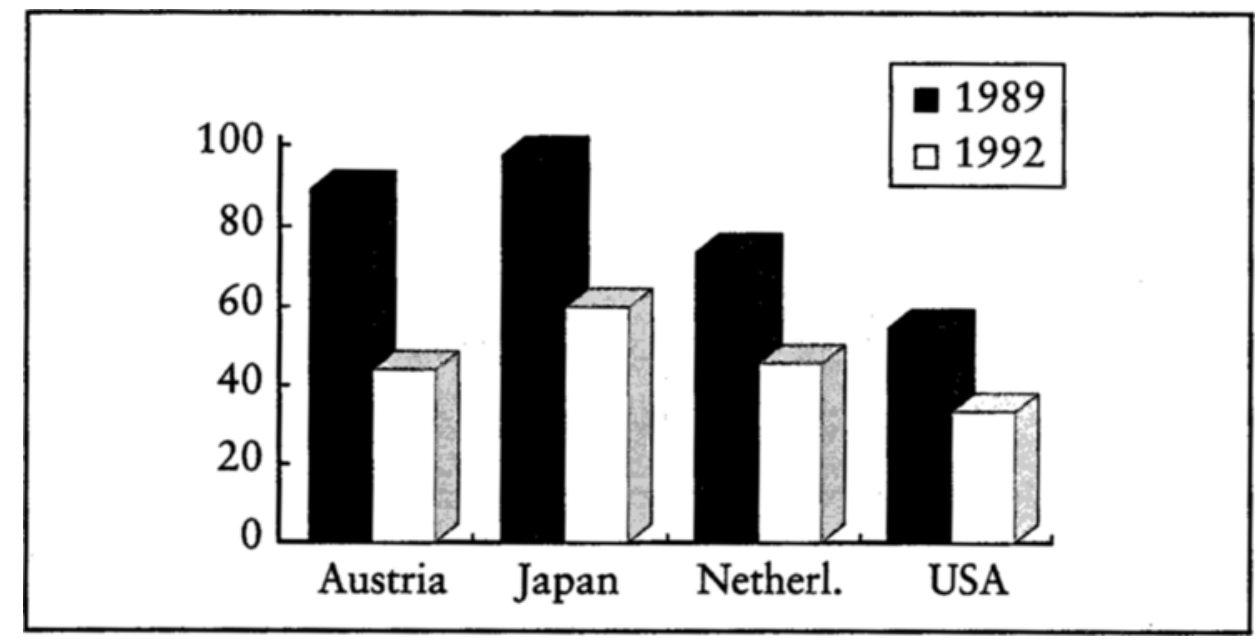

The most popular use of computers at schools in 1992 was to teach students how to use this new technology. Many students were attending computer education classes. The use of computers as tools in existing subjects was still marginal, as shown in Figure 7. The percentage of students using computers in other subjects was even less than the percentages in mathematics.

The integration of computers in lessons was still seen as requiring considerable additional time investments (Figure 8). This is a major concern. Future use of ICT in education means integration into the daily practice of learning and teaching. Time needs to be made available for teachers for such a change in education practice.

The expectations regarding the added value of computers were quite high, as shown by the opinions of school principals (Figure 9). 
FIGURE 7. Percentage of students in lower secondary schools working with computers in informatics and mathematics classes

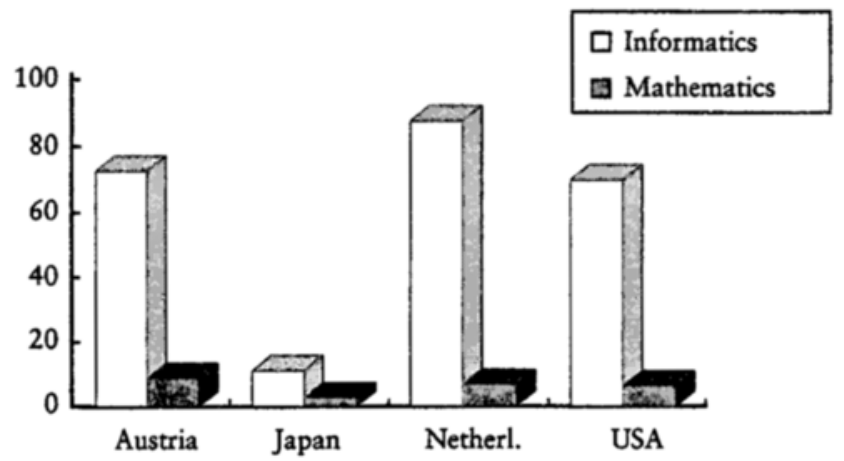

FIGURE 8. Percentage of lower secondary schools reporting insufficient time to integrate computers in lessons

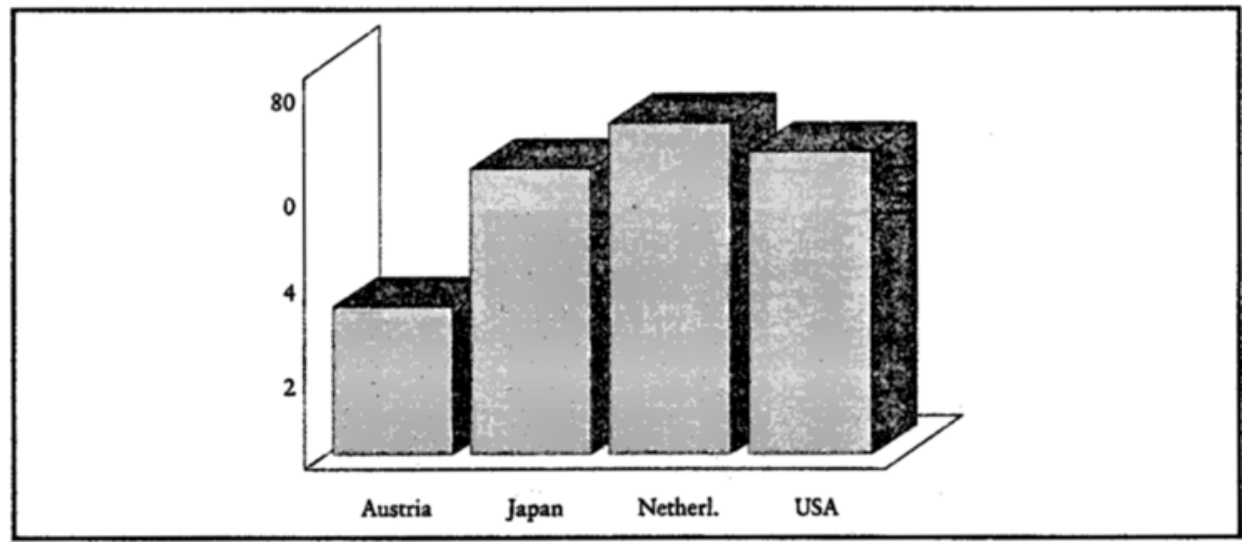

FIGURE 9. Percentage of lower secondary school principals who say that students are more attentive when computers are used

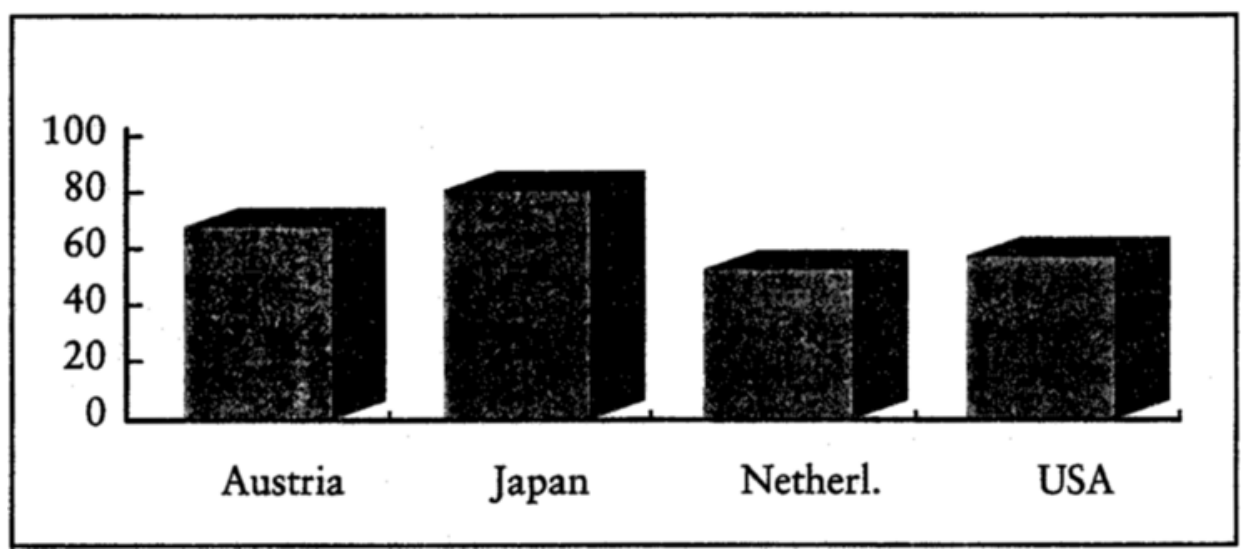

Prospects, vol. XXVII, no. 3, September 1997 
Many analyses were conducted on the CompEd data. For instance, Tuijnman and Brummelhuis (1993), Brummelhuis (1995), and Janssen Reinen (1996) showed the complex interactions of a number of factors influencing the degree of infusion of computers in the school curriculum (see Figure 10). It is important that policy makers understand that there is not a single factor that determines the integration of technology in education, but a group of interrelated factors which may differ in different stages of introducing information technology in education. Besides, certain necessary conditions have to be fulfilled, such as having a computer co-ordinator in each school.

\section{En route to the future}

Our analysis so far leads to two conclusions. First, our society increasingly requires learning situations responding to the need for flexibility (adapting to different needs), accessibility (learning when and whenever suits best) and support (an adequate learning infrastructure to assist learners). To make this happen, more emphasis should be given to student-oriented arrangements, and ICT provides powerful possibilities to realize this. Teachers, being key actors in learning and teaching processes, need to be trained in designing and organizing such innovative teaching and leaming environments. The learning infrastructure of the schools needs to change accordingly, both the content of what is being taught, as well as the materials and technical infrastructure (see Figure 2).

A second conclusion drawn from the CompEd study is that in the early 1990s ICT use in education was predominantly the use of computers, reflecting usage characterized as substituting for already existing didactical functions. The integration of technology in the daily practice of school is a process influenced by many different factors.

So the question is how to get en route! This question will be discussed by applying a system analysis point of view.

\section{A SYSTEMS APPROACH}

From the perspective of a systems analysis approach, we could regard society as the relevant environment of education. Education is defined here as the set of all educational practices; society as the place where education finds its people and resources, and to which it delivers its results. Schools and teacher-training institutes are, among other institutions, subsystems of the education system.

A system tends to pursue an equilibrium with its environment. It tends to organize its internal processes and exchange with the environment in such a way that it stays stable and viable. To do so, systems have to cope with the complexity of their surroundings by controlling variety. The variety of educational needs in society, for example, is balanced with the variety the schools can accommodate. No school can meet all of the individual learning characteristics of its students. In most cases, this is not much of a problem and most people accept the fact that a school can offer a limited variety of learning possibilities. However, in order to stay in balance with the (learning) needs of society, schools have to maintain their level of variety above a certain threshold. When the learning offerings of a school drop below that level, too many student-learning needs cease to be met and the 
FIGURE 10. Factors influencing the implementation of computer use in education

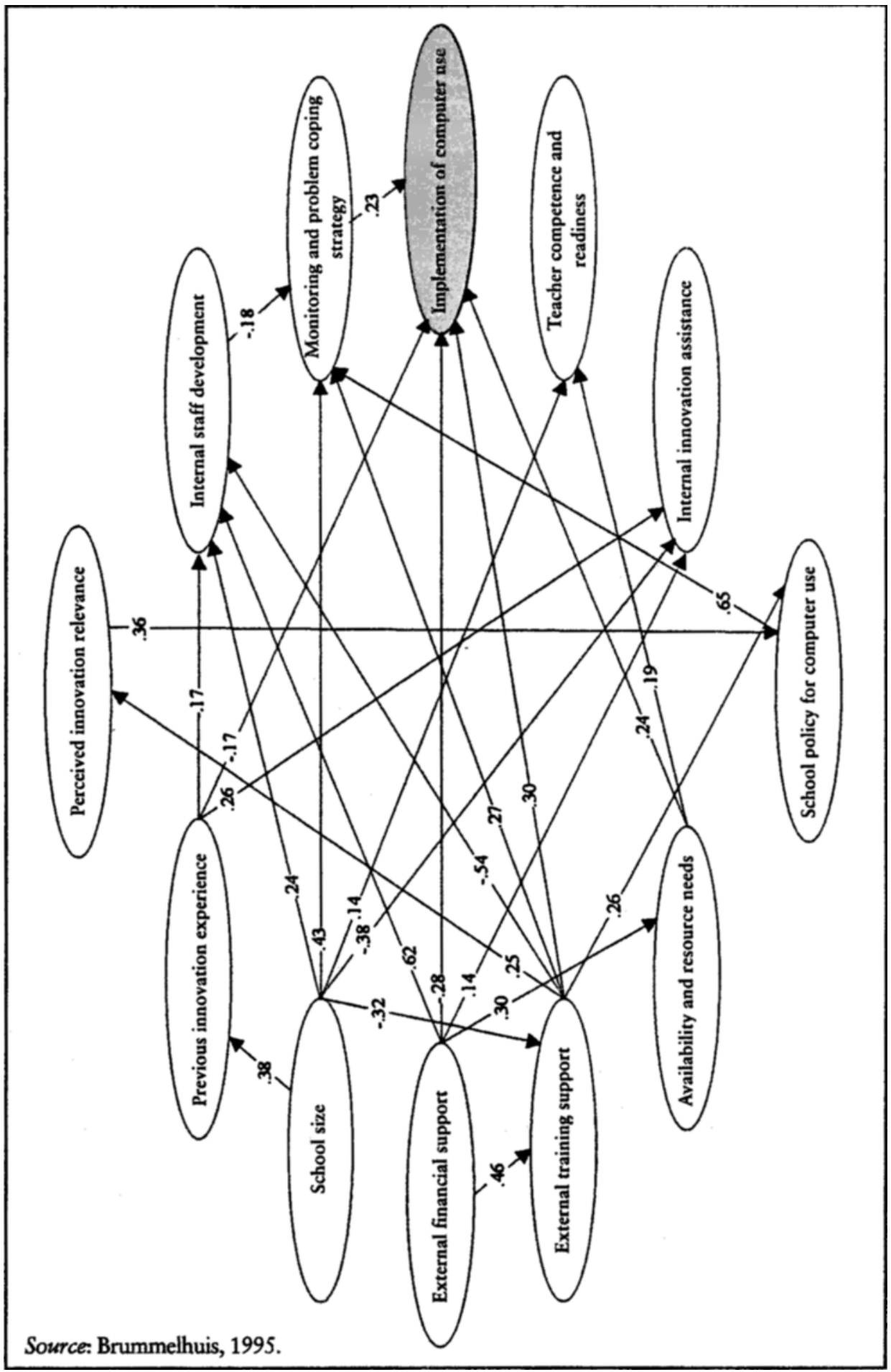

Prospects, vol. XXVII, no. 3, September 1997 
system gets out of balance. This imbalance could subsequently result in a decreasing number of registrants, a rise in dropouts, less public and/or political support, increase of classroom troubles, etc.

Numerous subsystems surround schools, such as teacher-training institutes, institutions for curriculum development, test development, school support institutes, educational publishers, furniture providers, educational software developers and others. Each of them has a specific function for education. Together they act as the safe-keepers of education. Whenever education has a need, expressed by the educators themselves, by the management or government administration, one of the safe-keepers will react with some sort of service by implementing small but important changes. In doing so, their support activities are not only defined by the existing education system but, in turn, keep the education system within the margins of controllable variability. They are designed to act in this way. But this makes them more the custodians of the present situation than the change-agents of education. This is a fundamental problem if one wants to bring about real change in education.

Besides these continuous adaptations, there is another kind of change emerging in education, namely change that goes beyond the boundaries of controlled variety. As long as education succeeds in answering the needs of society, it fulfils its function towards society and it stays stable and viable. But when the demands that society puts on education can no longer be met by more variety, the system itself (i.e. education) needs to change.

It is our belief that this is the case nowadays-that our society has moved towards a new paradigm, characterized by the 'information society'. This demands a new relationship between education and society or, in other words, implies a need for the transformation of education as well as new definitions of education. These new definitions of education will come from the learning needs and possibilities in the information society. They should not be regarded as developing linearly out of today's education. The consequences for education of the transformation from the industrial society into the information society are depicted in Figure 11.

In order to facilitate this transformation, it is required that the education system revises its relations with society, takes its needs seriously and gives its demands the highest priority. These demands were already mentioned in the first section as the challenges facing the education system.

\section{Developing a future for learning}

In order to prepare schools and teachers for education of the future, schools and teachertraining institutes should shift their focus from serving the current style of education to serving what emerges as the education of the future. They have to create both room and opportunities in their programmes for such a transformation. This causes a dilemma, as schools and teacher-training institutes cannot refrain completely from providing current education with teachers that can function in the existing situation.

A solution to this dilemma is to create a transition period from the present situation towards a future situation in which education will get its new shape. This implies stimulating and strengthening the development of something 'new' while the 'old' still exists. 
FIGURE 11. Consequences of ICT on education

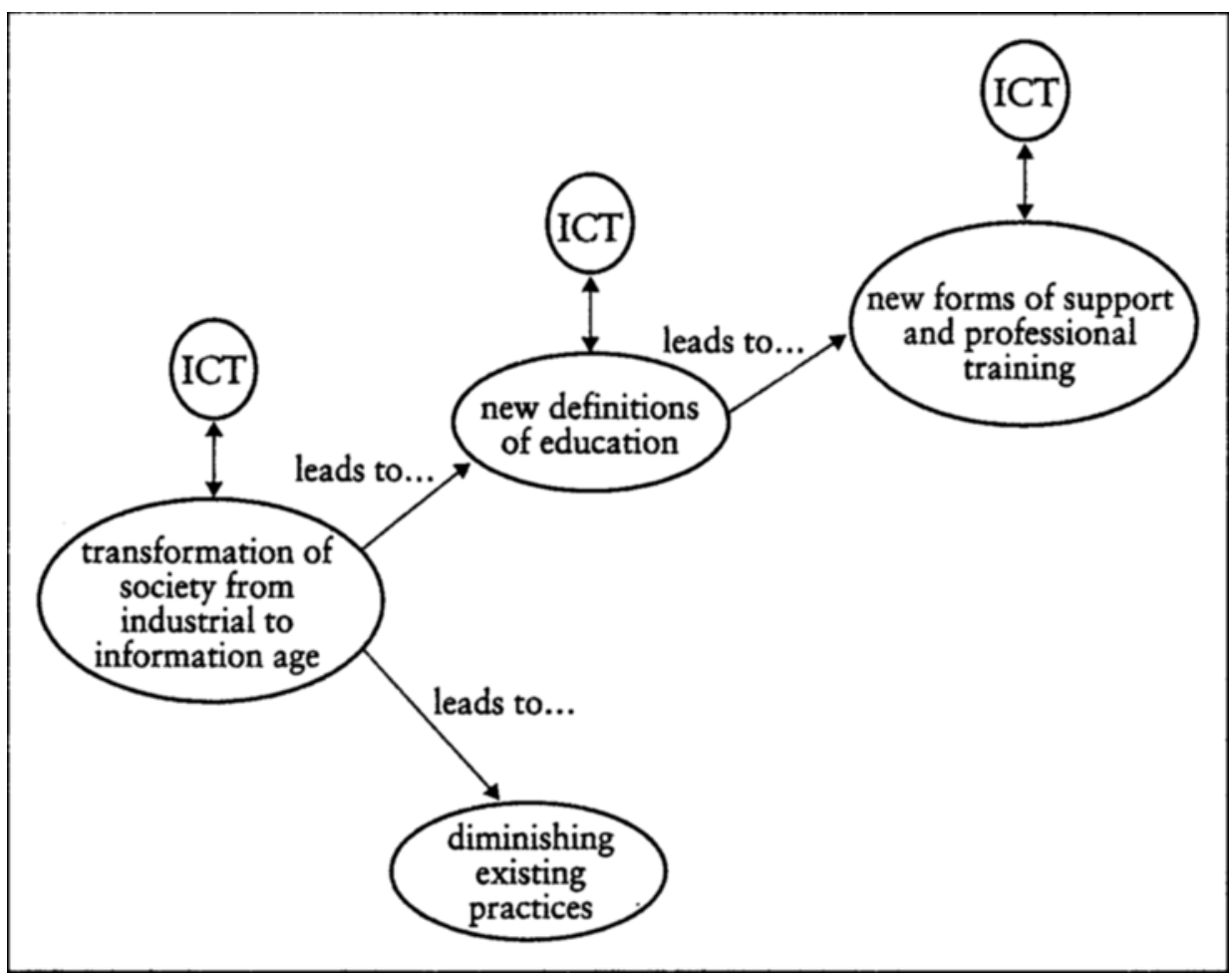

During such a transition process the 'old' needs care and attention, but should not prevent the 'new' from growing. 'Old', that is our present schools and teacher-training institutes, should be challenged to transform into 'new'. But at the same time, the 'new' needs stimulation and incentives, and should not be hampered by the 'old' trying to continue its previous equilibrium with its environment.

This demands a programme of action that has to provide bridges from 'old' to 'new'. The programme has to be designed in such a way that it creates opportunities for new definitions of education and at the same time challenges educators from existing practices to participate. However, the main focus of the programme should be on generating and supporting 'emergent practices' of learner-oriented arrangements with ICT as a medium, as well as preparing both teachers and student-teachers for the 'emergent practices' in primary and secondary education. This refers to the use of ICT as a medium in the schools, but at the same time an aspect of the teaching profession and therefore of teacher (inservice) training. A coherent research and development programme, in combination with an adequate monitoring process of firsthand experiences, is expected to create a clear picture of both tomorrow's teacher training and the educational practices in the field for which teachers are being prepared. In 1996, the Committee on Multimedia in Teacher Training (COMMITT) proposed such a programme in its final report (COMMITT, 1996). 


\section{Note}

1. The first and third sections of this paper are based on a report of the Committee on Multimedia in Teacher Training (COMMITT); parts of the report have been used with permission. The second part is based on Pelgrum, 1996.

\section{References}

Brummelhuis, A.C.A. ten. 1995. Models of educational change: the introduction of computers in Dutch secondary education. Enschede, University of Twente.

COMMITT [Committee on Multimedia in Teacher Training]. 1996. First intermediate report. Enschede, University of Twenty.

Izkan, S.J. 1994. Assessing the future of telecomputing environments: implications for instruction and administration. Computing Teacher (Eugene, OR), vol. 22, no. 4, p. $60-64$.

Janssen Reinen, I.A.M. 1996. Teachers and computer use: the process of integrating information technology in the curriculum. Enschede, University of Twente.

Netherlands. Ministry of Education. 1992. Enter: the future. Zoetermeer, Ministry of Education.

Pelgrum, W.J. 1996. Information and communication technology (ICT) in education worldwide. Enschede, University of Twente.

Pelgrum, W.J.; Plomp, T. 1991. The use of computers in education worldwide. Oxford, Pergamon Press.

- - eds. 1993. The IEA study of computers in education: implementation of an innovation in 21 education systems. Oxford, Pergamon Press.

Pelgrum, W.J.; Janssen Reinen, I.A.M.; Plomp, T. 1993. Schools, teachers, students and compruters: a cross-national perspective. The Hague, the International Association for the Evaluation of Educational Achievement (IEA).

Simons, P.R.J.; Zuylen, J.G.G. van. 1995. De didaktiek van leren leren [The didactics of learning learning]. Tilburg, Mesoconsult.

Tuijnman, A.C.; Brummelhuis, A.C.A. ten. 1993. Predicting computer use in six systems: structural models of implementation indicators. In: Pelgrum, W.J.; Plomp, T., eds. The IEA study of computers in education: implementation of an innovation in 21 education systems, p. 189-227. Oxford, Pergamon Press.

Walker, D.F. 1986. Computers and the curriculum. In: Culbertson, J.A; Cunningham, L.L., eds. Microcomputers and education, p. 22-39. Chicago, The University of Chicago Press. 